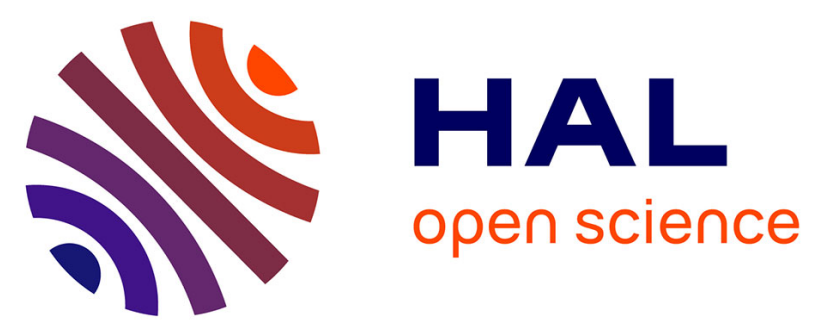

\title{
Asymmetric Intramolecular Buchner Reaction: From High Stereoselectivity to Coexistence of Norcaradiene, Cycloheptatriene, and an Intermediate Form in the Solid State
}

Benjamin Darses, Pascale Maldivi, Christian Philouze, Philippe Dauban, Jean-François Poisson

\section{To cite this version:}

Benjamin Darses, Pascale Maldivi, Christian Philouze, Philippe Dauban, Jean-François Poisson. Asymmetric Intramolecular Buchner Reaction: From High Stereoselectivity to Coexistence of Norcaradiene, Cycloheptatriene, and an Intermediate Form in the Solid State. Organic Letters, 2021, 23

(2), pp.300-304. 10.1021/acs.orglett.0c03774 . hal-03371078

\section{HAL Id: hal-03371078 \\ https://hal.science/hal-03371078}

Submitted on 8 Oct 2021

HAL is a multi-disciplinary open access archive for the deposit and dissemination of scientific research documents, whether they are published or not. The documents may come from teaching and research institutions in France or abroad, or from public or private research centers.
L'archive ouverte pluridisciplinaire HAL, est destinée au dépôt et à la diffusion de documents scientifiques de niveau recherche, publiés ou non, émanant des établissements d'enseignement et de recherche français ou étrangers, des laboratoires publics ou privés. 


\title{
Asymmetric intramolecular Buchner reaction: from high stereoselectivity to coexistence of norcaradiene, cycloheptatriene and an intermediate form in the solid state.
}

\author{
Benjamin Darses, ${ }^{\sharp, \dagger}$ Pascale Maldivi, ${ }^{\ddagger}$ Christian Philouze ${ }^{\S}$ Philippe Dauban ${ }^{\dagger}$ and Jean-François \\ Poisson $^{\S}$ \\ ${ }^{\S}$ Département de Chimie Moléculaire, CNRS - Université Grenoble Alpes UMR-5250 301 rue de la chimie, 38058 \\ Grenoble CEDEX 9, France \\ ${ }^{\dagger}$ Institut de Chimie des Substances Naturelles, CNRS UPR-2301, Université Paris-Sud, Université Paris-Saclay, 1 av. \\ de la Terrasse, 91198 Gif-sur-Yvette, France
}

Univ. Grenoble Alpes, CEA, CNRS, IRIG-SyMMES, 38000 Grenoble, France

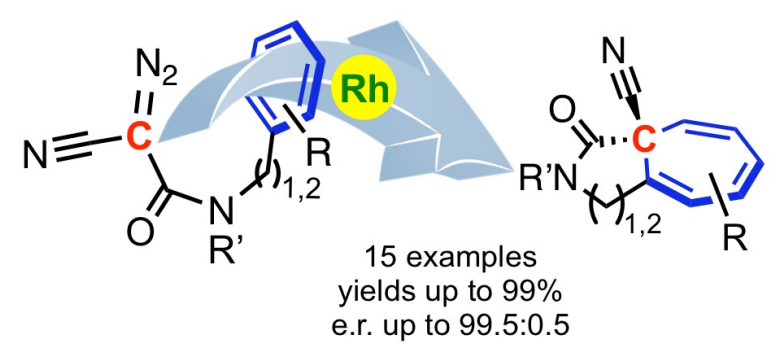

ABSTRACT: Bicyclic compounds bearing a quaternary stereogenic center have been obtained using asymmetric intramolecular Buchner reaction with excellent yields and level of enantioselectivity. X-ray crystallography determination of the absolute configuration of one product has led to the serendipitous observation of an unusual behavior within the crystal structure, with equilibrating norcaradiene and cycloheptatriene valence isomers at the solid state, as well as an even more unexpected intermediate form. DFT calculations were performed to support these observations.

Polycyclic structures containing seven-membered carbocycles are widely found in natural products. Among them, terpenes (daphnanes, tiglianes, ingenanes...) or alkaloids (colchicine, aconitine, cortistatins...) possess original architectures (Figure 1). However, the cycloheptane ring is not as common as the five- and six-membered rings within the commercially available building blocks.
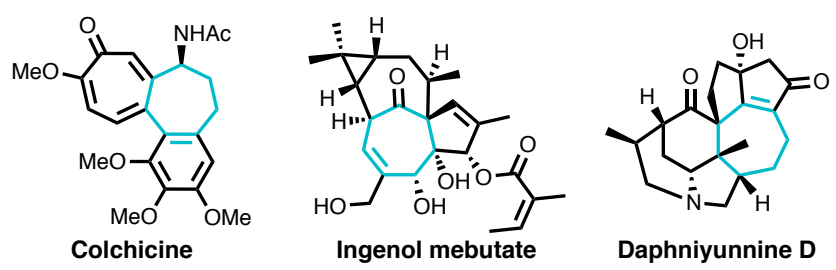

Figure 1. Seven-membered carbocycle-containing natural products.

Hence, seven-membered ring carbocycles must be built using synthetic methods such as ionic cyclizations or ring-closing metathesis, and also through elegant cycloadditions requiring the design of complex precursors. ${ }^{1}$ Alternatively, enlargement of broadly accessible smaller rings has also been considered..$^{\text {la }}$ 
Within the latter, the Buchner reaction is unique in its ability to induce a neutral expansive dearomatization, directly affording valuable functionalized cycloheptatrienes from widely available aromatic precursors. ${ }^{2}$ This original transformation consists in an unusual cyclopropanation of an aromatic ring by a carbene, delivering a norcaradiene, in equilibrium through an electrocyclic rearrangement with the generally more stable cycloheptatriene (Scheme 1$){ }^{3}$

\section{Scheme 1. The Buchner reaction.}

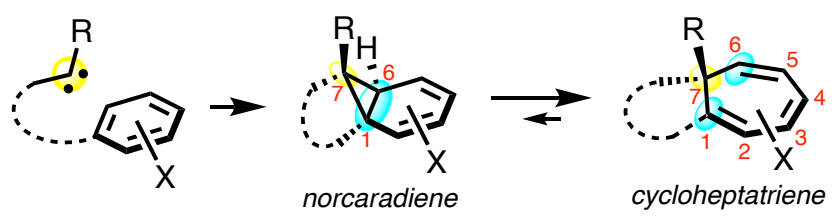

The intramolecular Buchner reaction is particularly efficient to rapidly access bicyclic sevenmembered ring-containing frameworks, while providing higher selectivities for the addition of the reactive carbenes, more prone to competitive $\mathrm{C}-\mathrm{H}$ insertions in intermolecular processes. While the generation of carbenes by thermal or photochemical decomposition of diazo precursors generally leads to mixtures of products, metal-catalyzed denitrogenation of diazo compounds can master the reactivity of carbene, ${ }^{4}$ allowing much more selective aromatic cyclopropanation and providing opportunities for synthetic developments. Though copper complexes were initially used, ${ }^{4 a}$ dirhodium(II) complexes rapidly showed greater catalytic activities, ${ }^{4 \mathrm{~b}, \mathrm{c}}$ and still remain the most widely used catalysts to efficiently perform the Buchner reaction.

Despite a great synthetic potential, very few examples of efficient asymmetric synthesis of cycloheptatrienes have been reported using the intramolecular Buchner reaction. ${ }^{5,6}$ Moderate to poor enantioselectivities are generally reported for Buchner reactions involving benzylic $\alpha$-diazoesters or $\alpha$-diazoamides. Moreover, these intramolecular processes often raise the issue of chemoselectivity that translates to the formation of mixtures of products and, thus, the isolation of the expected cycloheptatrienes in only moderate yields. ${ }^{5 \mathrm{~d}}$ Very recently, the use of a cationic chiral Ru-complex has led to a great improvement in the enantiocontrol of the reaction for the generation of tertiary stereogenic centers. ${ }^{7}$ Inspired by our recent studies on rhodium-catalyzed asymmetric amination, ${ }^{8}$ we have decided to investigate the use of chiral dirhodium(II) complexes in the intramolecular Buchner reaction for the formation of more challenging quaternary stereogenic centers. In this communication, we report an efficient synthesis of enantioenriched cycloheptatrienes through catalytic asymmetric intramolecular Buchner reaction using cyano substituted diazo derivatives. ${ }^{9,10}$

Our investigations started by reacting benzyl $\beta$-cyano $\alpha$-diazoacetamide $1 \mathbf{a}$ in the presence of $1 \mathrm{~mol} \%$ of the commercially available chiral dirhodium(II) complex (tetrakis[ $N$-phthaloyl- $(S)$-tertleucinate $]\left(\mathrm{Rh}_{2}[S \text {-pttl }]_{4}\right)$, in dichloromethane at $0{ }^{\circ} \mathrm{C}$ (Table 1, entry 1). We were delighted to observe the selective formation of the expected Buchner product 2a in 95\% yield and with a promising 87:13 enantiomeric ratio. Lowering the temperature to $-30{ }^{\circ} \mathrm{C}$ did not impede the efficiency of the reaction while improving the enantiomeric ratio to 90.5:9.5 (Table 1, entry 2). A screening was thus undertaken at this temperature to find the most efficient chiral catalyst.

Changing the amino acid side chain or introducing fluorine atoms on the phthaloyl moiety of the ligands proved deleterious to the asymmetric induction (Table 1, entries 3-5), while a tert-butyl group in position 4 of the phthaloyl group slightly improved the enantioselectivity (Table 1 , entry 6). ${ }^{11}$ The best result was obtained with the $S$-bpttl ligand, ${ }^{12}$ where the phenyl is replaced by a 2,3naphthoyl motif (Table 1, entry 7). However, other isomeric naphthalene derivatives led to lower enantiomeric ratio (Table 1, entries 8-9). The dosp or the btpcp ligands offered moderate to poor enantioselectivities in this transformation (Table 1, entries 10-11). ${ }^{13}$ Variation of the solvent also led to lower enantioselectivities (see Table S1, SI). Carrying the reaction at $-50{ }^{\circ} \mathrm{C}$ with the $S$-bpttl ligand allowed both an improvement of the enantiomeric ratio to $96: 4$ and the yield to $95 \%$ (Table 1, entry 12). Similar results were obtained using of $0.5 \mathrm{~mol} \%$ of rhodium catalyst (Table 1 , entry 13). ${ }^{14}$ 


\section{Table 1. Screening chiral ligands and temperature. ${ }^{[a]}$}

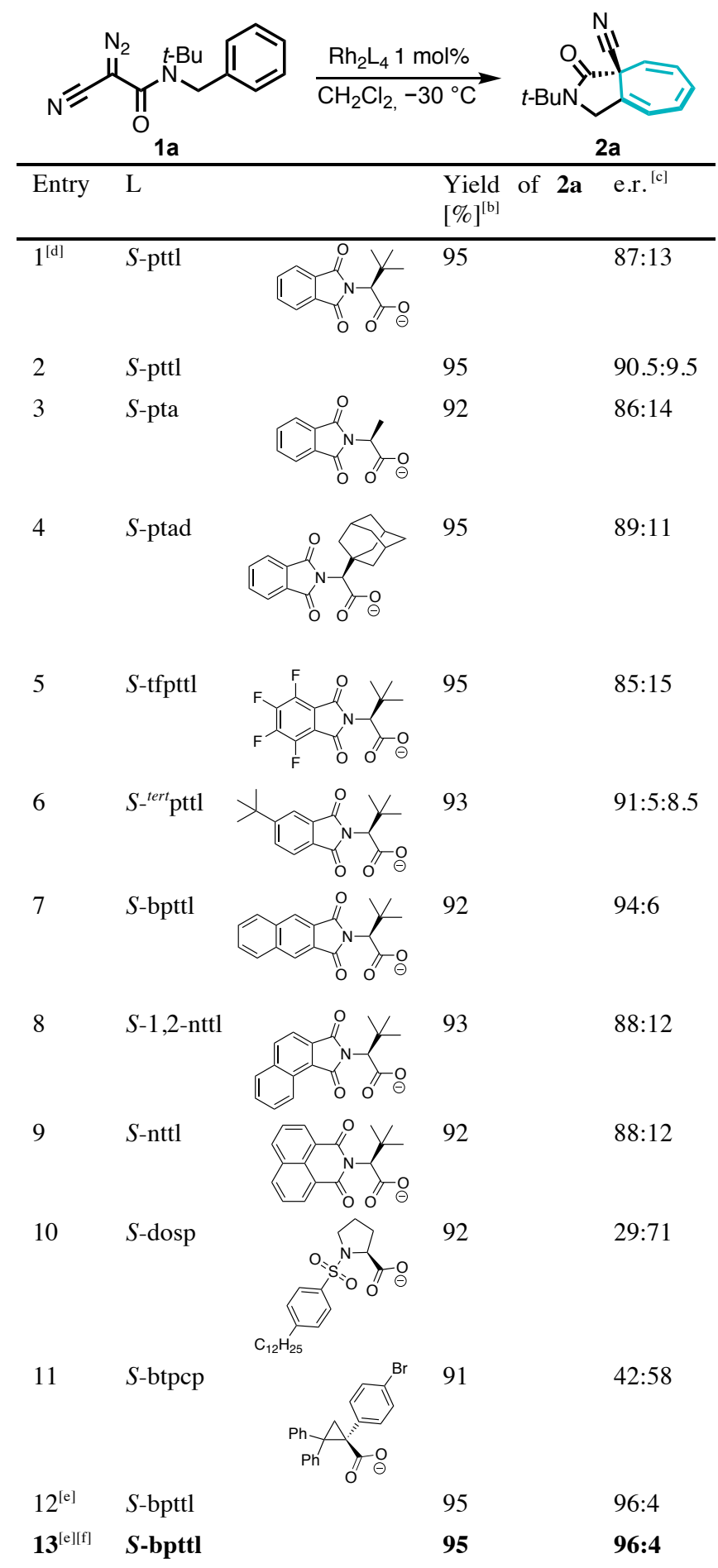

[a] Reaction conditions: to a solution of $\mathbf{1 a}\left(0.300 \mathrm{mmol}, 1.00 \mathrm{eq}\right.$.) in $\mathrm{CH}_{2} \mathrm{Cl}_{2}(6 \mathrm{~mL})$ at $-30{ }^{\circ} \mathrm{C}$, under an argon atmosphere, was added $\mathrm{Rh}_{2} \mathrm{~L}_{4}(3.0 \mu \mathrm{mol}, 1 \mathrm{~mol} \%)$. The mixture was stirred at this temperature for $2 \mathrm{~h}$. [b] Isolated yields after flash chromatography. [c] Determined by chiral HPLC. [d] Reaction carried at $0{ }^{\circ} \mathrm{C}$. [e] Reaction carried at $-50{ }^{\circ} \mathrm{C}$ for $24 \mathrm{~h}$. [f] 0.5 $\mathrm{mol} \%$ of $\mathrm{Rh}_{2} \mathrm{~L}_{4}$.

The optimized reaction conditions have then been applied to a variety of substituted aromatic derivatives (Scheme 2). Substitution of the aromatic ring in para position allowed the preparation of the corresponding Buchner products in excellent yields and enantioselectivities. 
The presence of an alkyl or a silyl group (2b-c) maintained a similar selectivity and halogens induced even greater enantiomeric ratio (2d-f). Nitrogen-containing functional groups such as an azide or a phthalimide also afforded the expected products both in high yields and selectivities (2g-h). The best enantiomeric ratios were obtained with aromatic bearing a substituent extending the $\pi$-conjugation such as a phenyl or a phenylacetylene moiety $(\mathbf{2} \mathbf{i}-\mathbf{j})$. The asymmetric formation of cycloheptatrienes is therefore very efficient, both in terms of yield and enantioselectivity, with moderately electron donating or withdrawing group at the para position of the aromatic ring. However, with more electron donating group, such as a methoxy (2k), the racemic product was obtained. This could be due to an equilibrating process involving an achiral spiro intermediate. ${ }^{15}$ This phenomenon has previously been postulated to explain such interconversion, and the presence of the nitrile substituent is probably favoring the push-pull racemization process. ${ }^{16}$ The reaction is not limited to $N$-tert-butyl derivatives as a $N$-benzyl amide (2l) also afforded the cycloheptatriene in good yield though in moderate enantioselectivity. It was also possible to introduce an additional methylene between the carbene and the aromatic ring with only a slight decrease of efficiency of the reaction. The 6,7bicyclic derivative $\mathbf{2 m}$ was thus isolated in $74 \%$ yield and 90.5:9.5 e.r.

\section{Scheme 2. Reaction Scope.}
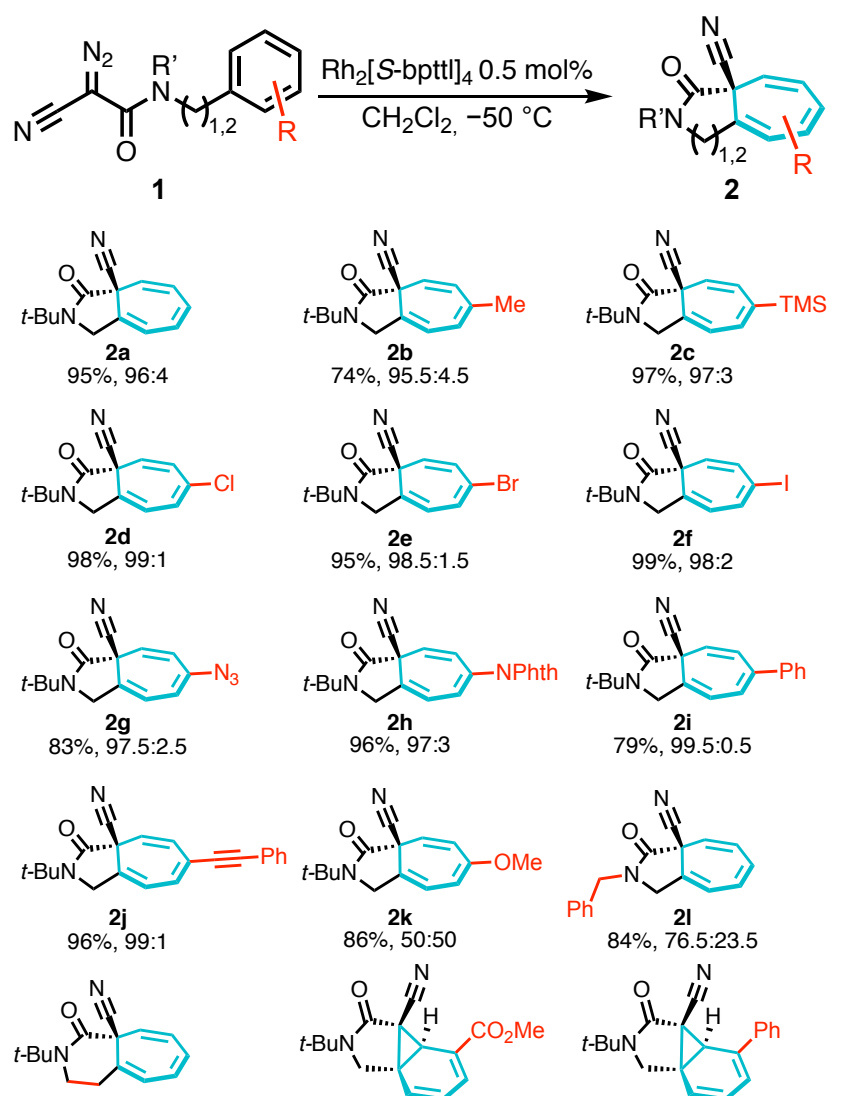

74\%, 2 90.5:9.5
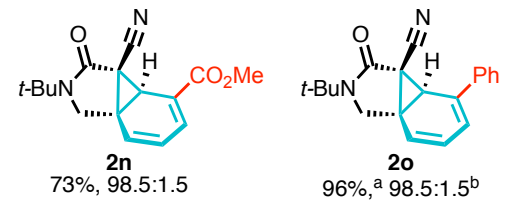

Reactions performed on $0.300 \mathrm{mmol}$ of substrate for $24 \mathrm{~h}$. Isolated yields, and e.r. determined by chiral HPLC. [a] 7:1 mixture of regioisomers. [b] For the shown major regioisomer.

An ester in the meta position proved very interesting as it leads to the isolation of a single regioisomer, notably as the norcaradiene product (2n) in $73 \%$ yield and an excellent enantioselectivity of 98.5:1.5. This product corresponds to the addition of the carbene to the most hindered of the two accessible positions of the aromatic ring. Similarly, a meta phenyl 
group afforded the same chemical reactivity, but in this case, the isolated product 20 is a 7:1 mixture of norcaradiene regioisomers, in favor of the most hindered one.

We decided to test the reliability of the transformation on a synthetically relevant scale. Applying the same reaction conditions on $5.00 \mathrm{mmol}(1.28 \mathrm{~g})$ of 1a delivered more than one gram of the expected product 2a with exactly the same yield and enantiomeric ratio. On 5.00 mmol scale, the catalyst loading could also be notably lowered to $0.05 \mathrm{~mol} \%$ (i.e. $3.6 \mathrm{mg}$ ), affording 2a in 93\% yield and an unchanged stereoselectivity (Scheme 3).

\section{Scheme 3. Gram-scale reaction.}

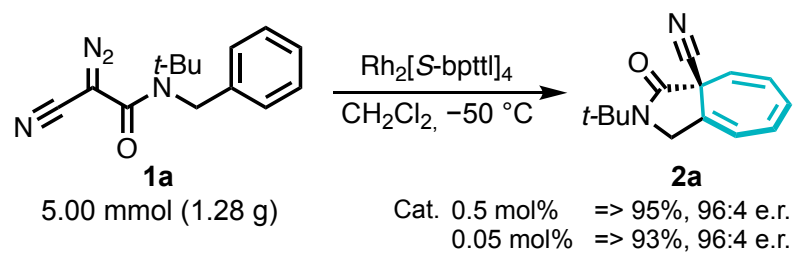

As aforementioned (Scheme 2), the substitution of the products can sometimes shift the cycloheptatriene/norcaradiene equilibrium in favor of the latter. It is therefore important to evaluate the position of the equilibrium between the two forms: observing the proton and carbon NMR chemical shifts of $\mathrm{C}^{6}-\mathrm{H}$ provides useful information. ${ }^{17}$ Indeed, they are known to be located at a weighted value reflecting the ratio between the two fast-equilibrating isomers. ${ }^{2}$ The structural isomers $\mathbf{2 i}$ and 2o, deriving respectively from a 4-phenyl or a 3-phenyl-substituted substrate, provide good comparison data. Whereas the $\mathrm{C}^{6}-\mathrm{H}^{1} \mathrm{H}$ and ${ }^{13} \mathrm{C}$ NMR chemical shifts respectively appears at 4.92 and $98.8 \mathrm{ppm}$ for $\mathbf{2 i}$, showing a vinylic character, those of compound 20 at 3.74 and $62.1 \mathrm{ppm}$ are more consistent with a cyclopropane ring (Figure 2). However, the unprecise position of the equilibrium frequently leads to contradictions. For example, $( \pm)-\mathbf{2 m}$ was described as a norcaradiene by Reisman, ${ }^{9 a}$ whereas Xu reattributed the structure of the same product to a cycloheptatriene. ${ }^{9 b}$ Observing the chemical shifts corresponding to $\mathrm{C}^{6}-\mathrm{H}$ which appear at 4.56 and $81.9 \mathrm{ppm}$ by ${ }^{1} \mathrm{H}$ and ${ }^{13} \mathrm{C} \mathrm{NMR}$, it is possible to evaluate that this compounds may better be represented as a cycloheptatriene rather than a norcaradiene.

In order to determine the absolute configuration of the prepared bicycles, we also decided to use the bromine anomalous diffusion at Mo K $\alpha$ wavelength, on compound 2e. ${ }^{18} \mathrm{We}$ first examined the NMR spectral data of this compound as we did for $\mathbf{2 i}, \mathbf{2 m}$ and $\mathbf{2 0}$. In this case, the chemical shifts of ${ }^{1} \mathrm{H}$ and ${ }^{13} \mathrm{C}$ NMR for $\mathrm{C}^{6}(\delta=5.13$ and $111.7 \mathrm{ppm}$ respectively; $\mathrm{CDCl}_{3}$, r.t.) clearly account for an even more pronounced $\mathrm{sp}^{2}$ character and therefore a highly prevalent cycloheptatriene form in solution.
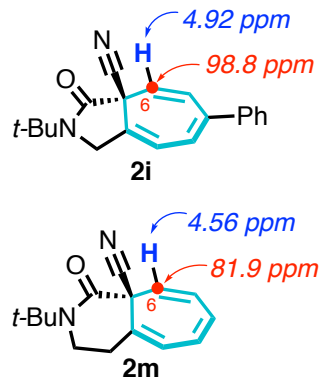
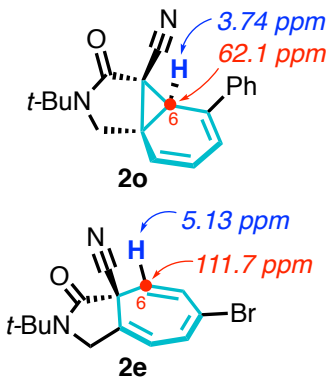

Figure 2. ${ }^{1} \mathrm{H}$ and ${ }^{13} \mathrm{C}$ NMR chemical shifts of $\mathrm{C}^{6}-\mathrm{H}$ for different products 2 . 
The absolute configuration of $2 \mathbf{e}$ was then determined to be $R$ by single-crystal X-ray crystallography. Interestingly, the asymmetrical unit displays two types of molecular forms in sharp contrast with the NMR observations in solution (Figure 3). The form $\mathbf{A}$ appears as a statistical disorder of the two valence isomers of $2 \mathbf{e}$ : the norcaradiene A-NCD and the cycloheptatriene A-CHT, in a 0.512/0.488 ratio. On the other hand, the form $\mathbf{B}$ is a slightly thermally agitated structure, that seems to be structurally laying at the intermediacy of the two extreme valence isomers. The $\mathrm{C}^{1}-\mathrm{C}^{6}$ distance of 1.853(9) $\AA$ is indeed between those of A-NCD and A-CHT (1.56(4) $\AA$ and $2.475 \AA$ respectively). Similarly, the $\mathrm{C}^{6}-\mathrm{C}^{7}-\mathrm{C}^{1}$ angle has a value of $77.2(5)^{\circ}$ for $\mathbf{B}$, far from the $109.5^{\circ}$ expected for a perfect tetrahedron or the $111(2)^{\circ}$ angle observed for A-CHT, but slightly closer to the $62(2)^{\circ}$ angle observed for A-NCD. Consequently, $\mathbf{B}$ could be seen as an artificially observable transition state between the two valence isomers A-NCD and A-CHT, stabilized within the crystalline matrix. To the best of our knowledge, this behavior has never been reported for this type of compounds. Moreover, in the solid state, the undeniable presence of a large amount of norcaradiene seems to indicate a network stabilization of this isomer.

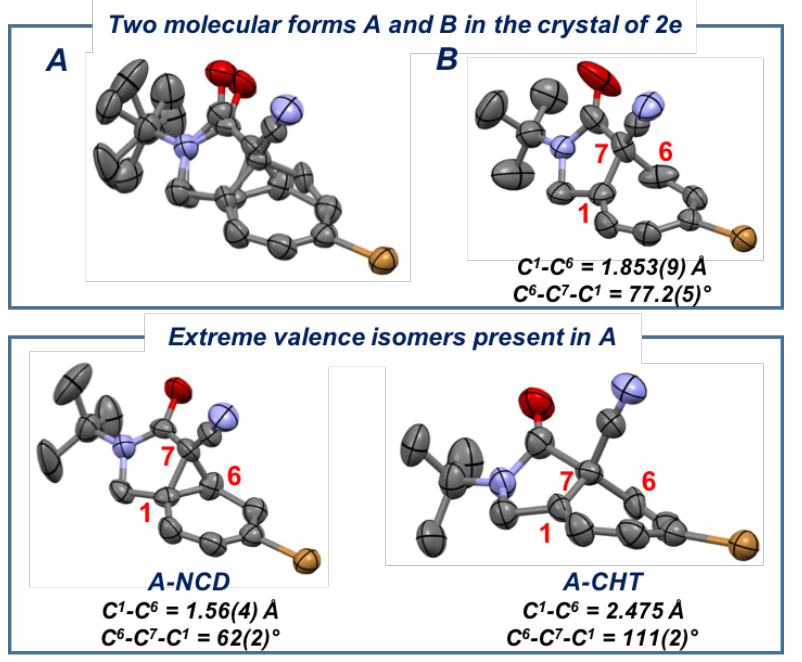

Figure 3. X-Ray structures of 2e: structures $A$ and $B$ present in the crystal, and decomposition of $A$ into its valence isomers.

The observation of both forms of $\mathbf{2 e}$ in the solid state, including an intermediate structure, as well as its different behavior in solution, revealed by NMR, indicate an equivalent or close stability of the two isomers and a fast exchange between both. Although the equilibrium is a known phenomenon, the easy balance between the two isomers, by physical state modification, may lead to contradictory product descriptions, as well as an unexpected reaction of the misidentified isomer upon condition modifications. We thus decided to model the thermodynamics profile of the isomers of $\mathbf{2 e}$ at $298 \mathrm{~K}$ using Density Functional Theory (DFT) calculations to evaluate the Gibbs energies of the norcaradiene and cycloheptatriene isomers (see SI for details). The optimized geometries thus showed a weak stabilization of $-3.6 \mathrm{kcal}$ $\mathrm{mol}^{-1}$ in favor of the cycloheptatriene form (in accordance with the NMR observation). Moreover, the activation free energy for the interconversion, computed at $6.7 \mathrm{kcal} \mathrm{mol}^{-1}$, is low and consistent with a possible fast exchange between the two valence isomers.

It is worth noting that optimized geometrical parameters are also in very good agreement with the experimental crystal data (see Table S2, SI). In particular, the calculated transition state (TS) structure is close to the observed form $\mathbf{B}$ found in the crystal of $\mathbf{2 e}$ (Figure 3): a $\mathbf{C}^{1}$ - 
$\mathrm{C}^{6}$ distance of $1.91 \AA$ and a $\mathrm{C}^{6}-\mathrm{C}^{7}-\mathrm{C}^{1}$ angle of $79.5^{\circ}$ : the stabilization of this unconventional form $\mathbf{B}$ within the crystalline matrix is quite puzzling, and to the best of our knowledge unprecedented.

In conclusion, we have reported an efficient strategy to prepare enantioenriched sevenmembered carbocycle-containing bicyclic skeletons. The asymmetric intramolecular Buchner reaction allowed the highly stereoselective installation of a quaternary stereogenic center, delivering a library of diversely substituted products. The unexpected observation of a compound present as the cycloheptatriene form in solution, but as a mixture of cycloheptatriene and noracardiene in the solid state prompted us to undergo some DFT calculation to rationalize this observation. Further investigations on this striking valence isomerization in solution or in the crystalline structure are currently under progress, so is the calculation of the enantiodetermining transition state with the chiral catalyst to rationalize the origin of the enantioselectivity.

\section{ASSOCIATED CONTENT}

\section{Supporting Information}

The Supporting Information is available free of charge on the ACS Publications website.

Experimental procedures, characterization data, computational details and crystallographic data (PDF)

\section{AUTHOR INFORMATION}

\section{Corresponding Author}

Benjamin Darses - Département de Chimie Moléculaire (DCM), team SeRCO, CNRS - Université Grenoble Alpes UMR5250301 rue de la chimie, 38058 Grenoble CEDEX 9, France; orcid.org/0000-0002-2284-5931;

Email: benjamin.darses@univ-grenoble-alpes.fr

\section{Authors}

Pascale Maldivi - Univ. Grenoble Alpes, CEA, CNRS, IRIG-SyMMES, 38000 Grenoble, France; orcid.org/0000-0003-20081090

Christian Philouze - Département de Chimie Moléculaire (DCM), team SeRCO, CNRS - Université Grenoble Alpes UMR5250301 rue de la chimie, 38058 Grenoble CEDEX 9, France

Philippe Dauban - Institut de Chimie des Substances Naturelles, CNRS UPR-2301, Université Paris-Sud, Université ParisSaclay, 1 av. de la Terrasse, 91198 Gif-sur-Yvette, France; orcid.org/0000-0002-1048-5529

Jean-François Poisson - Département de Chimie Moléculaire (DCM), team SeRCO, CNRS - Université Grenoble Alpes UMR-5250 301 rue de la chimie, 38058 Grenoble CEDEX 9, France; orcid.org/0000-0002-4982-7098

\section{Notes}

The authors declare no competing financial interest.

\section{ACKNOWLEDGMENT}

We wish to thank the Labex ARCANE and CBH-EUR-GS (ANR-17-EURE-0003) for their financial support. The NanoBioICMG platforms (FR 2607), the Département de Chimie Moléculaire and the Institut de Chimie des Subtances Naturelles are acknowledged for their technical and/or financial support.

\section{REFERENCES}

(1) (a) E. J. Kantorowski, M. J. Kurth, Expansion to Seven-Membered Rings. Tetrahedron 2000, 56, 4317-4353. (b) M. A. Battiste, P. M. Pelphrey, D. L. Wright, The Cycloaddition Strategy for the Synthesis of Natural Products Containing Carbocyclic Seven-Membered Rings. Chem. Eur. J. 2006, 12, 3438-3447. (c) K. E. O. Ylijoki, J. M. Stryker, [5 + 2] Cycloaddition Reactions in Organic and Natural Product Synthesis. Chem. Rev. 2013, 113, 2244-2266. (d) T. V. Nguyen, J. M. Hartmann, D. Enders, Recent Synthetic Strategies to Access Seven-Membered Carbocycles in Natural Product Synthesis. SYNTHESIS 2013, 45, 845-873. (e) K. T. de Oliveira, B. M. Servilha, L. de C. Alves, A. L. Desiderá, T. J. Brocksom, The Synthesis of Seven-Membered Rings in Natural Products, in Studies in Natural Products Chemistry, Vol.42, Ch. 14 (Ed.: Attaur-Rahman), Elsevier, 2014, pp. 421-463.

(2) (a) E. Buchner, T. Curtius, Synthese von Ketonsäureäthern aus Aldehyden und Diazoessigäther. Ber.Dtsch.Chem. Ges. 1885, 18, 2371-2377. (b) E. Buchner, T. Curtius, Ueber die Einwirkung von Diazoessigäther auf aromatische 
Kohlenwasserstoffe. Ber. Dtsch. Chem. Ges. 1885, 18, 2377-2379. (c) Z. Wang, Büchner Ring Expansion, in Comprehensive Organic Name Reactions and Reagents, John Wiley \& Sons, Inc. 2010, 562-566. (d) S. E. Reisman, R. R. Nani, S. Levin, Buchner and Beyond: Arene Cyclopropanation as Applied to Natural Product Total Synthesis. SYNLETT 2011, 2437-2442.

(3) O. A. McNamara, A. R. Maguire, The norcaradiene-cycloheptatriene equilibrium. Tetrahedron 2011, 67, 9-40.

(4) (a) A. Constantino, G. Linstrumelle, S. Julia, Étude des produits formés en traitant la diazo-1 diméthyl-3,3 phényl-4 butanone-2 par le cuivre et ses sels. Synthèses de la dimethyl-9,9 bicyclo[5.3.0]décèn-7 (1) one-8, de la dimethyl-3,3 tétralone2 et de la dimethyl-9,9 tricyclo[5.3.0.0 ${ }^{1,6}$ ]décanone-8. Bull. Soc. Chim. Fr. 1970, 912-920. (b) A. J. Anciaux, A. Demonceau, A. J. Hubert, A. F. Noels, N. Petiniot, P. Teyssié, Catalytic Control of Reactions of Dipoles and Carbenes; an Easy and Efficient Synthesis of Cycloheptatrienes from Aromatic Compounds by an Extension of Buchner's Reaction. J. Chem. Soc., Chem. Commun. 1980, 765-766. (c) A. J. Anciaux, A. Demonceau, A. F. Noels, A. J. Hubert, R. Warin, P. Teyssié, Transition-MetalCatalyzed Reactions of Diazo Compounds. 2. Addition to Aromatic Molecules: Catalysis of Buchner's Synthesis of Cycloheptatrienes. J. Org. Chem. 1981, 46, 873-876.

(5) (a) C. N. Slattery, S. O'Keeffe, A. R. Maguire, Electronic effects of aryl-substituted bis(oxazoline) ligands on the outcome of asymmetric copper-catalysed $\mathrm{C}-\mathrm{H}$ insertion and aromatic addition reactions. Tetrahedron: Asymmetry 2013, 24, 1265-1275. (b) X. Xu, X. Wang, P. Y. Zavalij, M. P. Doyle, Straightforward Access to the [3.2.2]Nonatriene Structural Framework via Intramolecular Cyclopropenation/Buchner Reaction/Cope Rearrangement Cascade. Org. Lett. 2015, 17, 790793. (c) Y. Liu, Y. Deng, P. Y. Zavalij, R. Liub, M. P. Doyle, An efficient route to highly enantioenriched tetrahydroazulenes and $\beta$-tetralones by desymmetrization reactions of $\delta, \delta$-diaryldiazoaceto-acetates. Chem. Commun. 2015, 51, 565-568. (d) T. Hoshi, E. Ota, Y. Inokuma, J. Yamaguchi, Asymmetric Synthesis of a 5,7-Fused Ring System Enabled by an Intramolecular Buchner Reaction with Chiral Rhodium Catalyst. Org. Lett. 2019, 21, 10081-10084.

(6) Intermolecular reaction under flow conditions: a) G. S. Fleming, A. B. Beeler, Regioselective and Enantioselective Intermolecular Buchner Ring Expansions in Flow. Org. Lett. 2017, 19, 5268-5271.

(7) T. T. N. Phan, M. Tone, H. Inoue, I. Fujisawa, S. Iwasa, Highly stereoselective intramolecular Buchner reaction of diazoacetamides catalyzed by a Ru(II)-Pheox complex. Chem. Commun. 2019, 55, 13398-13401.

(8) (a) A. Nasrallah, V. Boquet, A. Hecker., P. Retailleau, B. Darses, P. Dauban, Catalytic Enantioselective Intermolecular Benzylic $\mathrm{C}\left(\mathrm{sp}^{3}\right)-\mathrm{H}$ Amination. Angew. Chem., Int. Ed. 2019, 58, 8192-8196; Angew. Chem. 2019, 131, 8276-8280. (b) A. Nasrallah, Y. Lazib, V. Boquet, B. Darses, P. Dauban, Catalytic intermolecular C( $\left.\mathrm{sp}^{3}\right)-\mathrm{H}$ amination with sulfamates for the asymmetric synthesis of amines. Org. Process. Res. Dev. 2020, 24, 724-728.

(9) (a) R. R. Nani, S. E. Reisman, $\alpha$-Diazo- $\beta$-ketonitriles: Uniquely Reactive Substrates for Arene and Alkene Cyclopropanation. J. Am. Chem. Soc. 2013, 135, 7304-7311. (b) S. Mo, J. Xu, Chemospecific Intramolecular Buchner Reaction Catalyzed by Copper(II) Acetylacetonate. ChemCatChem 2014, 6, 1679-1683.

(10) For asymmetric synthesis of norcaradienes using cyano substituted $\alpha$-diazoesters, see : K. L. Smith, C. L. Padgett, W. D. Mackay, J. S. Johnson, Catalytic, Asymmetric Dearomative Synthesis of Complex Cyclohexanes via a Highly Regio- and Stereoselective Arene Cyclopropanation Using $\alpha$-Cyanodiazoacetates. J. Am. Chem. Soc. 2020, 142, 6449-6455.

(11) F. G. Adly, M. G. Gardiner, A. Ghanem, Design and Synthesis of Novel Chiral Dirhodium(II) Carboxylate Complexes for Asymmetric Cyclopropanation Reactions. Chem. Eur. J. 2016, 22, 3447-3461.

(12) S. Kitagaki, M. Anada, O. Kataoka, K. Matsuno, C. Umeda, N. Watanabe, S.-I. Hashimoto, Enantiocontrol in Tandem Carbonyl Ylide Formation and Intermolecular 1,3-Dipolar Cycloaddition of $\alpha$-Diazo Ketones Mediated by Chiral Dirhodium(II) Carboxylate Catalyst. J. Am. Chem. Soc. 1999, 121, 1417-1418.

(13) (a) H. M. L. Davies, B. D. Doan, Asymmetric synthesis of the tremulane skeleton by a tandem cyclopropanation/cope rearrangement. Tetrahedron Lett. 1996, 37, 3967-3970. (b) C. Qin, V. Boyarskikh, J. H. Hansen, K. I. Hardcastle, D. G. Musaev, H. M. L. Davies, D2-Symmetric Dirhodium Catalyst Derived from a 1,2,2-Triarylcyclopropanecarboxylate Ligand: Design, Synthesis and Application. J. Am. Chem. Soc. 2011, 133, 19198-19204.

(14) Increasing the concentration or lowering further the temperature to $-60^{\circ} \mathrm{C}$ both resulted in the inhibition of the reaction.

(15) A. R. Maguire, P. O'Leary, F. Harrington, S. E. Lawrence, A. J. Blake, Dynamic Equilibria in the Products of Intramolecular Buchner Additions of Diazoketones to Aryl Rings Bearing Methoxy Substituents. J. Org. Chem. 2001, 66, $7166-7177$.

(16) However, this example is in sharp contrast with the $99 \%$ e.e. obtained by Iwasa on a similar structure bearing a $\mathrm{H}$ in place of the $\mathrm{CN}$ (see ref. 7). The significantly lower pulling effect seems to prevent the racemization.

(17) K. Hannemann, Formation of Cycloheptatriene/Norcaradiene Systems in the Decomposition of Diaryldiazomethanes in Benzene. Angew. Chem., Int. Ed. Engl. 1988, 27, 284-285; Angew. Chem. 1988, 100, 273-274.

(18) Measurements were undertaken at room temperature on an orthorhombic single-crystal grown from compound 2e. The crystal has the following cell: $\mathrm{a}=9.806(2), \mathrm{b}=35.947(7), \mathrm{c}=8.0257(16)$ with the P21212 space group. 